SVU-International Journal of Veterinary Sciences 1 (1): 1-3, 2018

Print ISSN: 2535-1826

Online ISSN: 2535-1877

Letter to the editor

Open Access

\title{
Cutting-Edge Topics in Research on Veterinary Sciences
}

\section{Seddik Hammad ${ }^{1 *}$, Yasser A. Ahmed ${ }^{2}$, Ashraf Elghoneimy ${ }^{3}$, Jehan Ragab Daoud ${ }^{4}$}

${ }^{1}$ Department of Forensic Medicine and Veterinary Toxicology, ${ }^{2}$ Department of Histology, ${ }^{3}$ Department of Pharmacology, ${ }^{4}$ Department of Food Hygiene, Faculty of Veterinary Medicine, South Valley University, Qena, Egypt

\section{Abstract}

We are pleased to announce the first edition of the SVU-International Journal of Veterinary Sciences (SVU-IJVS). We hope that this journal will advance the field of animal sciences and related biomedical disciplines. SVU-IJVS is particularly interested to publish any work -of a high quality-in the field of animal sciences. Beside conventional animal-related work, interdisciplinary articles i.e. medicine, biology, bioinformatics and mathematics which may not be published by the narrow windows journals, are highly appreciated in the SVU-IJVS. We hope that SVU-IJVS will play a positive role in this field of research.

Keywords: SVU-IJVS, Animals, Publications, Journals, Research

Received: May 28, 2018

Accepted: May 29, 2018

Published: June 30, 2018

*Corresponding Author: Seddik Hammad

E-mail: Seddik.hammad@vet.svu.edu.eg

Citation: Hammad et al., 2018, Cutting-edge topics in research on veterinary sciences. SVUIJVS, 1 (1): 1-3. 
Animal science is a highly enriched and rapidly growing field of research. Searching in May 2018 for "Animal” in PubMed [Title/Abstract] resulted in 19 841, 21 711, 23 294, 24 665, 25 679, 26 945, 27328 and 27811 hits in 2010, 2011, 2012, 2013, 2014, 2015, 2016 and 2017, respectively. On average, more than 1000 articles are added on top of every year in this field of research. Therefore, it is expected that numerous new journals every year are launched and partially covered this exciting field of research. Some of these unspecialized journals consider the animal field of research as a tool i.e. for drug approval. Whereas, the main focus of veterinary specialized journals is animal-based studies only. To bridge this gap between non-veterinary and veterinary journals, the Faculty of Veterinary Medicine-South Valley University, Egypt has recently launched SVU-IJVS (https://portal.svu.edu.eg/svusrc/index.php/ijvs) focusing on basic veterinary sciences, human and applied as well as systems medicine. This means that the SVU-IJVS will be concerned to receive and publish articles (original article, short communication, review arti- cles, case study, editorials, and highlights) in the following disciplines*: (1) Basic veterinary sciences. This includes but is not limited to anatomy, histology, biochemistry, biophysics, physiology, microbiology, parasitology, nutrition, pharmacology, toxicology, forensic sciences, pathology, andrology, zoonotic diseases, behaviour, husbandry and wild life, Field related research and case studies, including internal medicine, surgery, theriogenology, obstetrics, poultry and fish diseases, environmental sciences as well as food hygiene, (3) Applied biomedical research i.e. food additives and/or protective synthetic and natural agents, nanotechnologies for drug development and compound delivery, (4) Cutting-edge articles in translational medicine, e.g., transgenic mice, humanized mouse models, stem cell therapy and computational as well as systems medicine. This includes upto-date technologies of biomedical veterinary relevance, e.g., modern artificial insemination, biobanking, publically available datasets mining and 2D/3D cell/tissue analysis, (5) 3Rs topics (discussed in Hammad et al., 2018). The SVU-IJVS will also be keen to consider 
biomedical articles from biology, biomedicine, and agriculture-related disciplines. There will be no publication costs associated with this newly launched journal. In addition to the tightly controlled peer review process, the well-recognized Editors-in-Chief will accept only manuscripts of high quality. We are sure that SVU-IJVS journal will contribute to advancements in the veterinary sciences.

*Footnote: This editorial reproduces parts of LETTER TO THE EDITOR,
NEWS AND VIEWS published in Archives of Toxicology, 2018 (Hammad et al., 2018).

\section{References}

Hammad S, Othman A, Abdel-Wareth AAA, Ahmed H, Abdel-Daim MM, Gherbawy YA. (2018). From basic research to applied veterinary sciences: current status, challenges and perspectives. Arch Toxicol. [Epub ahead of print]. 